\title{
Assessment of Women's Satisfaction with Childbirth Experience after Utilization of Pain Management Practices at Al-Elwyia Maternity Teaching Hospital
}

\author{
Rabea Mohsen Ali \\ Maternal and Neonate Nursing Department, College of Nursing/University of Baghdad, Iraq
}

\begin{abstract}
A quasi-experimental study conducted on non-probability of (30) women whom admitted to Al-Elwyia Maternity Teaching Hospital suffering from labor pain for the period of ( $4^{\text {th }}$ July 2018 through $24^{\text {th }}$ October 2018). The results how that the highest percentages of non- pharmacological method used was frankincense oil, and related to women perception of labor pain they are assessed high as general, and they are accounted 24(96.0\%). The study concluded that women's satisfaction with childbirth experience after utilization pain management practice's items showed good status, since highly evaluation was obtained, and that reflected the positive site of effectiveness for the intervention which were applicable indeed. So that construction continuous education program about non-pharmacological pain management practices to all midwife working in delivery room and department of maternity is need.
\end{abstract}

Keywords: Assessment, satisfaction, childbirth, Pain Management.

\section{Introduction}

Childbirth is an important life event in women's life, and it is a multifaceted experience. The mother's satisfaction during the birthing process is the most frequently reported indicator in the evaluation of the quality of maternity services. A positive birth experience is associated with an increased mother-child bond, maternal abilities, and contributes to her sense of accomplishment and self-esteem ${ }^{(1)}$.

\section{Methodology}

A quasi-experimental study design was conducted on purposive sample, of (30) women whom admitted to Al-Elwyia Maternity Teaching Hospital suffering from labor pain. Study implemented for the period of ( $4^{\text {th }}$ July 2018 through $24^{\text {th }}$ October 2018). Data collection will be gathered by application one of non-pharmacological

\section{Corresponding Author:}

Dr. Rabea Mohsen Ali

$\mathrm{PhD}$, Maternal and Neonate Nursing Department, College of Nursing/University of Baghdad, Iraq e-mail: rabea_ali@ymail.com method include: (frankincense, jasmine, \& olive oils), massage, body movement and change position (squatting, side-lying, \& standing), breathing technique, and therapeutic touch), and by used questionnaire format which consisted of two parts, including nonpharmacological method Birth Satisfaction Scale (BSS-R), which is a 10-item, self-report scale that was reduced from the original 30-item BSS. Descriptive and inferential statistical analyses were used to analyze the data.

\section{Results}

Table (1): Type of Pain Management Method Uses

\begin{tabular}{|c|l|c|c|}
\hline \multirow{2}{*}{ No. } & \multirow{2}{*}{ Items } & \multicolumn{2}{|c|}{ Yes } \\
\cline { 3 - 4 } & & F & \% \\
\hline 1 & Essential Oils & 17 & $56.6 \%$ \\
\hline 3 & Side-Lying Position \& Breathing & 4 & $13.3 \%$ \\
\hline 4 & Squatting Position & 4 & $13.3 \%$ \\
\hline 5 & Massage & 1 & $3.3 \%$ \\
\hline 6 & Massage \& Standing position & 1 & $3.3 \%$ \\
\hline 7 & Therapeutic Touch \& standing & 1 & $3.3 \%$ \\
\hline 9 & Breathing Technique & 1 & $3.3 \%$ \\
\hline 10 & Therapeutic Touch \& side-lying position & 1 & $3.3 \%$ \\
\hline
\end{tabular}


Table (1) results show that "Essential Oils" method have recorded the high and first ordered method, and accounted (56.6\%), then followed with "Squatting Position, and Side-Lying Position \& Breathing" method, and accounted (13.3\%), Massage, Massage \& Standing position, Therapeutic touch \& Standing, breathing technique, $\&$ side lying position accounted (3.3\%).

Table (2): Women's Satisfaction with Childbirth Experience after utilization Pain Management Practices

\begin{tabular}{|c|c|c|c|c|c|c|c|}
\hline No. & Items & Groups & $\mathbf{F}$ & $\%$ & MS & RS\% & Ass. \\
\hline \multirow{2}{*}{1} & \multirow{2}{*}{$\begin{array}{l}\text { I came through childbirth virtually unharmed } \\
\text { (unscathed). }\end{array}$} & Yes & 3 & $10.0 \%$ & \multirow{2}{*}{0.100} & \multirow{2}{*}{10.0} & \multirow{2}{*}{$\mathrm{L}$} \\
\hline & & No & 27 & $90.0 \%$ & & & \\
\hline \multirow[b]{2}{*}{2} & \multirow{2}{*}{ I thought my labor was excessively long.* } & Yes & 7 & $23.3 \%$ & \multirow{2}{*}{0.766} & \multirow{2}{*}{76.6} & \multirow{2}{*}{$\mathrm{L}$} \\
\hline & & No & 23 & $76.7 \%$ & & & \\
\hline \multirow{2}{*}{3} & \multirow{2}{*}{$\begin{array}{l}\text { The delivery room staff encouraged me to make } \\
\text { decisions about how I wanted my birth to progress. }\end{array}$} & Yes & 30 & $100 \%$ & \multirow{2}{*}{1.000} & \multirow{2}{*}{100} & \multirow{2}{*}{$\mathrm{H}$} \\
\hline & & No & 0 & $0.00 \%$ & & & \\
\hline \multirow{2}{*}{4} & \multirow{2}{*}{ I felt very anxious during my labor and birth.* } & Yes & 8 & $26.7 \%$ & \multirow{2}{*}{0.733} & \multirow{2}{*}{73.3} & \multirow{2}{*}{$\mathrm{L}$} \\
\hline & & No & 22 & $73.3 \%$ & & & \\
\hline \multirow{2}{*}{5} & \multirow{2}{*}{ I felt well supported by staff during my labor and birth. } & Yes & 30 & $100 \%$ & \multirow{2}{*}{1.000} & \multirow{2}{*}{100} & \multirow{2}{*}{$\mathrm{H}$} \\
\hline & & No & 0 & $0.00 \%$ & & & \\
\hline \multirow{2}{*}{6} & \multirow{2}{*}{ The staff communicated well with me during labor. } & Yes & 28 & $93.3 \%$ & \multirow{2}{*}{0.930} & \multirow{2}{*}{93.3} & \multirow{2}{*}{$\mathrm{H}$} \\
\hline & & No & 2 & $6.7 \%$ & & & \\
\hline \multirow{2}{*}{7} & \multirow{2}{*}{ I found giving birth a distressing experience.* } & Yes & 26 & $86.7 \%$ & \multirow{2}{*}{0.133} & \multirow{2}{*}{13.3} & \multirow{2}{*}{$\mathrm{H}$} \\
\hline & & No & 4 & $13.3 \%$ & & & \\
\hline 8 & I folt out of control during mubiuth oynorionco * & Yes & 2 & $6.7 \%$ & 0023 & 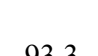 & $\mathrm{I}$ \\
\hline 0 & 1 Hell out or contror during my birth experience. & No & 28 & $93.3 \%$ & 0.933 & 93.3 & $\mathrm{~L}$ \\
\hline 0 & I v & Yes & 8 & $26.7 \%$ & 0266 & 266 & $\mathrm{I}$ \\
\hline 9 & I was not distressed at all during labor. & No & 22 & $73.3 \%$ & 0.206 & 20.6 & $\mathrm{~L}$ \\
\hline & & Yes & 30 & $100 \%$ & & & \\
\hline 10 & The delivery room was clean and hygienic. & No & 0 & $0.00 \%$ & 1.000 & 100 & $\mathrm{H}$ \\
\hline
\end{tabular}

*Items reversed measuring scale (i.e. Negative Response), and that revere an assessments scores.

Table (2) shows that results show that women's satisfaction with childbirth experience after of utilization pain management practice's items, concerning study group assigned that the observed responses regarding positive items numbers $(3,5,6$, and 10) and are high as assessed generally, and they are accounted 4(40.0\%), while left over item number ( $1 \& 9)$ has low assessment, and accounted $2(20 \%)$. In relation to negative items numbers $(2,4$, and 8$)$ are low assessed generally, and they are accounted 3(30.0\%), while left over item number 7 "I found giving birth a distressing experience" has high assessed, and accounted $1(10 \%)$. In sum, it could be concluded that women's satisfaction with childbirth experience after utilization pain management practice's items showed good status, since highly evaluation was obtained, and that reflected the positive site of effectiveness for the intervention which were applicable indeed.

\section{Discussion}

Nonpharmacological Method: The researcher depended on WHO recommendations when using method of non-pharmacological pain management which included breathing technique, changing position, massage, aromatherapy and other techniques used for healthy pregnant women requesting pain relief during labor depending on a woman's preference ${ }^{(2)}$. Especially when some women prefer changing positions which include squatting, side-lying position and standing. These positions help relieve pain, and speed labor ${ }^{(3)}$. 
Then as observed in this study the researcher teaches woman how to apply breathing technique based on evidence-based studies ${ }^{(4 \& 5)}$. Relative to use of massage technique. The massage increasing the production of endorphins in the body that reduce the transmission of signals between nerve cells and thus lower the severity of pain ${ }^{(6)}$. Finally, the researcher attempted to use aromatherapy for women due to that the researcher noted the uses of these aromatherapy have many benefit such as promoting relaxation, decrease anxiety and reduce labor pain. ${ }^{(4,7 \& 8)}$.

Assessing Women's Satisfaction with Childbirth Experience: The results observed that the most important experience in the life of women, who want to play a central role in childbirth process is giving birth to a child. In addition, the satisfaction derived from this experience is extremely important for her, her baby's healthand development of positive family support. Such that, adverse childbirth experience can lead to many problems as postpartum depression, posttraumatic stress disorder, tendency to miscarriage, preference for cesarean delivery, negative feelings against baby, difficulty in adaptation to maternal role, breastfeeding problems, and in addition it will have an effect on a woman's interpersonal relationships, and her wellbeing emotionally and physically $(9 \& 10)$. Women's satisfaction is effected by many factors including medical care, health care professionals, her hospital room, and her relationship with her environment; however studies performed have emphasized critical importance of integrated approach ${ }^{(11)}$. The importance of the approach to pain during labor, and continuity of care were indicated for the popularization of normal vaginal delivery which makes pregnancy, labor, and childbirth a favorable experience for the mother ${ }^{(12)}$. Moreover, the control concept differentiates from one woman to another and some of them are anxious around controlled along of labor, while other their anxious include the shared in decisions related to labor process. As a consequence, letting woman to decide the decisions and informed choices are essential factors that made woman sense convinced with the labor process ${ }^{(13)}$. Therefore, a copy with pain by using technique of non-pharmacological pain relief is one factor that link to gratify with labor process. Because that woman who faced low level of labor pain has positive level of satisfaction of birth versus those with intense level of pain in labor ${ }^{(10)}$.

\section{Conflict of Interest: Nil}

\section{Source of Funding: Self}

Ethical Clearance: Is obtained from theMinistry of Health/Al-Russafa Health Directorate (Al-Elwyia maternity teaching hospital), and All laboring women participants in the research - have been approved before the questionnaire is started.

Recommendations: The study recommended Construction continuous education program about non-pharmacological pain management practices to all midwife working in delivery room and department of maternity.

\section{References}

1. Bélanger-Lévesque, M. N., Pasquier, M., RoyMatton, N., Blouin, S., \& Pasquier, J. C. Maternal and paternal satisfaction in the delivery room: a cross-sectional comparative study. BMJ Open, (2014),4(2).

2. World Health Organization. WHO recommendation on relaxation techniques for pain management during labor. Reproductive Health Library; Geneva:(2018).

3. Ricci S.: Essentials of Maternity, Newborn \& Women's Health Nursing, 3rd ed., Walters Kluwer Health, Lippincott Williams \& Wilkins; (2013), pp. 439-440.

4. Vakilian K.; Davoud Abadi M., and Seyed Zadeh Aghdam N.: The Effects of breathing techniques on the length of labor active phase and its second stage in women's first labor. CMJA, (2014), 3 (4), pp: 666-673.

5. Yuksel, H.; Cayir Y.; Kosan Z., and Tastan K. : Effectiveness of breathing exercises during the second stage of labor on labor pain and duration: a randomized controlled trial. Journal of Integrative Medicine, (2017), 15(6), pp: 456-461.

6. Smith, C. A., Levett, K. M., Collins, C. T., \& Jones, L.: Manual healing methods including massage and reflexology for pain management in labor. Cochrane Database of Systematic Reviews, (2011), (9).

7. Joseph, R. M., \& Fernandes, P.: Effectiveness of jasmine oil massage on reduction of labor pain among primigravida mothers. Nitte University Journal of Health Science, (2013), 3(4), 104.

8. Chauhan K., Rani S., BansalP.: Effectiveness of olive oil back massage on reduction of labor pain 
during first stage of labor. International Journal of Nursing \& Midwifery Research, (2016), 3(2 \& 3).

9. O’Connor, T.G., Heron, J., Golding, J., Beveridge, M. and Glover, V.: Maternal antenatal anxiety and children behavioral/ emotional problems at 4 years: report from the longitudinal study of parents and children. The British Journal of Psychiatry, (2002), 180, 502-508.

10. Goodman, P., Mackey, M. C., \& Tavakoli, A. S.: Factors related to childbirth satisfaction. Journal of advanced nursing, (2004), 46(2), 212-219.
11. Mckee, M.D., Cunningham, M., Jankowski, K.R.B. and Zayas, L. Health-related functional status in pregnancy: relationship to depression and social support in a multi-ethnic population. (2001). Obstetrics and Gynecology, 97, 993-998.

12. McVeigh, C., and Smith, M. . A comparison of adult and teenage mother's self-esteem and satisfaction with social support. Midwifery, (2000), 16, 269276.

13. Gibbins, J., \& Thomson, A. M.: Women's expectations and experiences of childbirth. Midwifery, (2001), 17(4), 302-313 